Correction to Metall. Trans. B, 1991, vol. 22B, pp. 918-21

Dissolution Equilibrium of Magnesium Vapor in the Liquid Iron by Xiaodong Zhang, Qiyong Han, and Dong Chen

Page 920:

In column 2,15 th line from the top, the equation should read as follows: [pct $\mathrm{Mg}]=0.058899 P_{\mathrm{Mg}}^{2.103}(r=0.979)$

\title{
Page 921:
}

In column 1 , the last equation should read as follows:

$$
\text { [pct } \mathrm{Mg}]=0.059 P_{\mathrm{Mg}}^{2.1}
$$

